\title{
Arbor
}

\section{Un drama nuevo, de Manuel Tamayo y Baus: las paradojas del comediante y del juego dramático}

\section{Jesús Rubio Jiménez}

Arbor CLXXVII, 699-700 (Marzo-Abril 2004), 677-690 pp.

Un drama nuevo figura entre los textos dramáticos canónicos del siglo $X X$. En este ensayo se realiza una indagación para tratar de explicar sus claves: sintesis entre drama histórico y alta comedia; el drama de tesis; la perfecta construcción dramática; pero sobre todo, una reflexión acerca de las peculiaridades de las gentes del teatro: su inestabilidad emocional, la envidia, la dificultad para diferenciar entre lo vivido y lo representado. La ambigüedad es el territorio fronterizo donde deben vivir por ello las gentes del teatro: entre el ser y el parecer, la realidad y la ficción.

El gran tema de Un drama nuevo es así el propio teatro, que se apropia de las vidas de quienes se dedican a él mucho más allá de los escenarios, invadiendo hasta su vida intima.

Un drama nuevo se estrenó en Madrid, en el Teatro de la Zarzuela, el 4 de mayo de 1867 con un éxito apoteósico. Aunque su autor se ocultaba bajo el seudónimo de Joaquín Estébanez, era un secreto a voces, que era obra de Manuel Tamayo y Baus (1829-1898), reputado dramaturgo que formaba parte de la Real Academia de la Lengua desde 1858 tras una brillante trayectoria en los escenarios españoles. Antes de que acabara el año se habían agotado cuatro ediciones sueltas del drama y hasta finales de siglo se reeditó al menos en otras tres ocasiones, considerado desde muy pronto uno de los dramas canónicos del siglo XIX. 
Hijo de cómicos -su padre fue el primer actor y director de escena José Tamayo y su madre, Joaquina Baus y Ponce de León, era ya primera dama del teatro del Príncipe en 1825- estuvo desde niño vinculado al teatro y aún no había cumplido los doce años cuando ya se asomó a las tablas con un arreglo del drama Genoveva de Brabante. Más aún: de sus dos hermanos, Andrés fue también autor dramático y Victorino un actor notable. Nada parece más natural en este ambiente que se casara con una mujer, María Emilia Máiquez, cercana al teatro, ya que era sobrina del célebre actor Isidoro Máiquez.

Desde niño, se volviera hacia donde se volviera, Tamayo se encontraba con el teatro. En su familia, pero también en el entorno donde el teatro era uno de los elementos de sociabilidad que impregnaba todas las facetas de la vida urbana. Prendió en él la afición al teatro y no tardaría en comenzar a estrenar obras propias convirtiéndose en los años cincuenta en uno de los dramaturgos más estimados y versátiles de su tiempo tanteando todos los géneros desde la zarzuela o la función áulica a la alta comedia o la tragedia clasicista. A la larga, sin embargo, sólo unas pocas piezas se recuerdan en los manuales literarios puesto que ha desaparecido su teatro de los escenarios como casi todo el del siglo XIX. El último bastión que resiste de la que en su día fue considerada una sólida fortaleza es Un drama nuevo. Resiste pero lo hace solamente en ediciones apenas frecuentadas por los estudiantes de Filología Hispánica y por algún lector curioso. Es decir, perdura más por la inercia de ser un texto clásico que por su presencia escénica ${ }^{1}$. ¿Quién recuerda ya haber asistido a una función de este drama? A tal estado de abandono ha llegado el teatro de repertorio español. Ni siquiera su carácter de pieza clásica es aliciente para que sea puesto en escena.

$\mathrm{Y}$ sin embargo, hay que decirlo pronto y claro, Un drama nuevo, es una pieza excelente que merece ser puesta en escena y hasta es probable que guste al público si se hace adecuadamente. Cuesta admitir que un drama que obtuvo una acogida extraordinaria que se prolongó durante medio siglo, alcanzando en vida del autor al menos siete ediciones, haya envejecido hasta el punto de quedar arrinconado definitivamente. Cuesta reconocer que dos críticos tan exigentes como Manuel de la Revilla y Clarín estuvieran equivocados por completo. Sostenía el primero que la obra era «un asombro», «una producción en que todo es admirable (incluso el lenguaje sentencioso), en la que palpita una inspiración gigante, en la que las pasiones humanas vibran al unísono con las que Shakespeare pintara en sus inmortales obras, en la fuerza dramática, el efecto escénico, el terror trágico y la atrevida originalidad de las situaciones, llega a 
un punto altísimo de perfección.» $\mathrm{Y}$ es una «producción, en suma, que basta, no ya para glorificar a un hombre, sino para enorgullecer a un pueblo» ${ }^{2}$. Clarín aún iba más lejos: «Bien puede asegurarse que pasarán siglos y, como no suceda a nuestros días alguna época de barbarie, Un drama nuevo seguirá siendo admirado como joya inapreciable del teatro español. En este drama hay fuerza y armonía; los dos elementos últimos de la belleza; la pasión de Alicia y Edmundo es de la raza de las pasiones que sintieron Romeo y Julieta, Francesca y Paolo, Federico y Casandra; el dolor de Yorick y sus lamentos son una mezcla del dolor y los lamentos de Otelo y de Lear; porque Yorick es esposo y padre, todo junto, y siente los celos del terrible Otelo y el abandono del miserable rey Lear ${ }^{3}$.

O erraban Revilla y Clarín o vivimos tiempos de barbarie, que bien puede ser. A su favor juega que ni uno ni otro simpatizaban ideológicamente con don Manuel que había derivado hacia el carlismo después de la revolución de 1868, apartándose del teatro para dedicarse a trabajos académicos y a dirigir la Biblioteca Nacional, y por tanto pocas simpatías personales podía suscitarles a estos liberales decididos defensores del espíritu de aquella revolución ${ }^{4}$. Algo diferente apreciaron en Un drama nuevo para expresarse así emparentándolo con el gran dramaturgo isabelino y a sus personajes con otros célebres de la literatura occidental. No lo hacían ya en el fragor de su primera difusión, sino pasados unos años, constituido ya en drama de repertorio, resistiendo mejor el paso del tiempo que sus piezas de alta comedia y dramas históricos que envejecieron con rapidez como la moral tradicional que les servía de fundamento y que él reivindicó siempre sin vacilaciones. Otras deben ser las claves de $U n$ drama nuevo para que no corriera la suerte de estas otras piezas. La primera que no partió sólo como en aquellas de una tesis moral a la que supeditaba el desarrollo del drama, sino que prefirió trabajar intensamente en el interior de este sin apriorismos cerrados, explorando posibilidades del juego teatral y en los conflictos de sus participantes.

Con tanta habilidad maneja los resortes teatrales -no en vano llevaba veinte años cultivando la precisa maquinaria de la alta comedia- que se ha llegado a sugerir que se adelantaba a Pirandello, otorgándole a su teatralidad una dimensión filosófica inexacta porque no era Tamayo precisamente un pensador dispuesto a salirse de la ortodoxia tradicional más estricta. Las motivaciones que subyacen en el preciso mecanismo escénico que es Un drama nuevo tienen más motivaciones escénicas que filosóficas. Es la mostración del proceso de montaje de una pieza nueva uno de los elementos que da unidad al drama más que una reflexión abstracta. La pieza aparece primero como manuscrito y al final, tras el re- 
parto y los ensayos, el espectador asiste al momento culminante de su representación. En ningún momento se olvida este anclaje y Tamayo no se pierde en especulaciones filosóficas ${ }^{5}$.

Tampoco es convincente una lectura que se apoye sin más en el tópico tradicional del mundo como teatro y la organización del drama en torno al tema del teatro dentro del teatro ${ }^{6}$. Ensartar un listado de precedentes de la utilización de estos tópicos acaba conduciendo a una nivelación excesiva. No se pueden barajar como si de naipes de la misma baraja se tratara dramas como Lo fingido verdadero, de Lope de Vega, Hamlet, de Shakespeare, Pedro de Urdemalas, de Cervantes, El gran teatro del mundo, de Calderón, o Kean ou désordre et génie, de Dumas ${ }^{7}$. La evidencia del acertado uso del teatro dentro del teatro considerado de manera general no es suficiente para explicar un éxito tan espectacular, aunque esto no quita que fuera uno de sus atractivos. Lo importante no es sólo la duplicación de la trama haciendo que en su momento culminante converjan las dos líneas planteadas, sino que es mucho más decisivo el análisis que a lo largo de todo el drama se realiza de las paradojas a las que viven abocados quienes consagran su vida a un arte de apariencias cuya finalidad es desvelar las apariencias de los comportamientos humanos.

En las páginas que siguen voy a indagar en algunas claves de lectura que a mi entender ayudan a situar este drama. La primera de ellas ya la he adelantado: Tamayo por una vez no se ciñó sólo a unos preceptos morales aplicados mecánicamente, sino que prefirió ahondar en las contradicciones de los personajes viviendo sus conflictos. Es decir, dotó de dramatismo a lo que en otros dramas suyos no era sino habilidad en el manejo de conflictos al servicio de demostración de tesis fijadas a priori. $\mathrm{Al}$ comienzo de Un drama nuevo se enuncia en boca de Shakespeare la tesis moral del drama:

Nunca faltará qué envidiar al que sea envidioso. Pone la envidia delante de los ojos antiparras maravillosas, con las cuales a un tiempo lo ve uno todo feo y pequeño en sí, y en los demás, todo grande y hermoso. Así, advertirás que los míseros que llevan tales antiparras no sólo envidian a quien vale más, sino también a quien vale menos, y juntamente los bienes y los males ${ }^{8}$.

Sin embargo, esta tesis pasa desapercibida en ese momento. Es un elemento más del diálogo y no se adivina su alcance. La fábula de $U n$ drama nuevo trasciende lo anecdótico para adquirir un valor más general mediante el propio juego dramático y no al revés. Acaso sea excesivo suscribir las comparaciones de Clarín y Revilla, quienes en sus respectivas poéticas teatrales otorgaban un valor de referencia siempre importante a los grandes modelos del pasado, pero es evidente que los personajes de Un drama nuevo tienen una consistencia no habitual en el 
teatro de su tiempo, no son modelos convenidos de virtud o de vicio, sino que tienen una complejidad que los hace atractivos.

El drama presenta a un grupo de cómicos que forman parte de la compañía teatral de Shakespeare en Inglaterra hacia 1605. Se disponen a poner en escena una obra nueva de un autor desconocido. El reparto de papeles suscita enfrentamientos y recelos. Yorick, un veterano actor cómico que está casado con la joven Alicia, le solicita al director de la compañía, Shakespeare, el papel de marido deshonrado. Esta petición ofende a Walton actor trágico de la compañía a quien correspondería tal papel y que molesto con la nueva situación planea cómo vengarse por su desplazamiento.

A esta fuente de tensiones se añade otra. Yorick es el padre adoptivo de Edmundo, pero entre éste y Alicia ha prendido la llama del amor y viven preocupados debatiéndose entre asumir con todas consecuencias su pasión amorosa y el remordimiento que les produce pensar que están ultrajando a Yorick a quien no deben sino consideración y agradecimiento. Walton en su búsqueda de venganza por haber sido despojado de un papel que consideraba suyo encontrará una forma de venganza, descubriendo a Yorick esta relación, que le deshonra.

El hallazgo singular de Tamayo en Un drama nuevo fue que este conflicto se hace coincidir en su momento culminante con el que plantea el drama nuevo que estrenan: ahí el Conde Octavio (representado por Yorick) es engañado por su esposa Beatriz (Alicia) con Manfredo (Edmundo), que es su hijo adoptivo. Landolfo (Walton) entrega al conde Octavio una carta en la que Manfredo propone a Beatriz una fuga. Octavio mata a Manfredo para evitarlo. En la representación, Yorick se sale de su papel de actor y mata a Edmundo porque ha llegado a saber por Walton el engaño de que está siendo objeto. El drama se cierra con Shakespeare dando unas explicaciones al público de lo que ha sucedido.

La fórmula constructiva utilizada no difiere de la de muchas piezas de alta comedia en las que dados un número reducido de personajes la trama consiste en combinarlos de tal manera que se produzcan parejas equívocas y las tensiones vayan acrecentándose hasta un momento en que cuando parece que ya no hay salida, una carta reveladora u otra explicación devuelve a cada uno a su sitio y se recobra la felicidad. La diferencia aquí es que los equívocos se duplican en el drama representado y la solución no es feliz, sino trágica. Tamayo, utiliza un paradigma que conocía muy bien, pero lo hace para negarlo. El espejo de la representación de la vida doméstica no devuelve al final la imagen placida de la convivencia familiar, sino la de la traición. No se confirma al final la felicidad, momentáneamente empañada por unos malentendidos, sino la desdicha. 
A mi entender importa más en Un drama nuevo la fisura que no la soldadura de las dos tramas en la que tanto se ha insistido. Dicho con otras palabras, aquel público estaba habituado a descodificar artefactos escénicos en los que tras complicados lances todo volvía a su sitio mientras que aquí se llega a unas situaciones paradójicas: a la negación de un modelo formal e ideológico (el de la alta comedia) y a plantear un asunto de mayor calado: la paradoja del comediante. ¿Debe o no debe identificarse con el papel que representa? ¿Es tan seguro el hogar doméstico como se pretende? ¿Son tan nítidos los límites de los afectos entre los esposos, entre padres e hijos?

Las preguntas, además, se formulan con sagacidad. No se trata simplemente de plantear la paradoja diderotiana mecánicamente sino que antes de su formulación se han ido disponiendo las cosas de tal manera que cuando Yorick o Walton pueden hacerse estas preguntas ya no tienen opción de elegir respuestas, sino que han confundido vida y teatro porque en sus vidas el teatro les ha conducido a vivir enajenados, fuera de la vida. Y el teatro los devuelve a su amarga realidad. El teatro les revela la vida. El teatro desvela la vida: ha perdido Yorick a su esposa y a su hijo adoptivo. Walton ha tenido que afrontar el cruel recuerdo de su pasado infeliz. El teatro les ha robado la vida.

Dilucidar este proceso por el que el teatro se apropia de las vidas de quienes se dedican a él parece ser el objetivo de Tamayo. Los personajes advierten que sus vidas van cambiando, que incluso las relaciones con sus seres más queridos se van modificando, pero no aciertan a ver las causas porque no encuentran el momento de analizarlas por estar totalmente embebidos en sus creaciones teatrales. Le sucede a Yorick, que advierte el alejamiento de Edmundo (I, 3) o el de Alicia (II, 3). O a Walton, cuya seguridad es más aparente que real, ya que vive con terror el ser desplazado de los papeles trágicos (II, 1) o la vuelta de su oscuro pasado (II, 9).

Ocurre, sin embargo, que la manera en que el teatro desvela la verdad es tal, que puede ser entendida a medias o producir la duda de que sea así puesto que es cosa de teatro. Al final de primer acto, Alicia se desmaya al oír a Yorick (Octavio) las palabras reveladoras de la infidelidad de la esposa en el drama que están ensayando. Se identifica en ellas. La ficción penetra en la realidad con tal fuerza, que la sustituye y destroza todas las precauciones para mantener oculta la verdad (I, 6, pp. 97-98). Yorick analiza correctamente el desmayo y entiende que su esposa ya no le ama y ama a otro. Así se lo confiesa a Edmundo:

Yorick.-Al oír que la llamaba esposa infiel, con palabras de esa maldita comedia que le sonaron a verdad, sobrecogióse de modo que llegó a perder el sentido. 
Edmundo.-¿Qué mucho, si es tan delicada y sensible que al más leve ruido inesperado se conmueve y altera? Ya os lo dijo Guillermo.

Yorick.-Ciertamente que me lo dijo. (Con ironía.) Alicia al desmayarse, pidió perdón.

Edmundo.-Turbada por la voz acusadora, su mente, como ciega máquina, siguió el impulso recibido. Guillermo os lo dijo eso también.

Yorick.-Tambièn me lo dijo, en efecto. (Con ironía, como antes.) Pero en mi pecho quedó leve espina; espina que fue muy pronto clavo encendido. Yo antes nada veía, en anda reparaba. Como la luz del sol, deslumbra la luz de la felicidad. Nublado el cielo de mi dicha, todo lo vi claro y distinto. (...) Ahora, a cada momento, reciben nuevo pábulo mis sospechas, porque ya Alicia ni siquiera intenta disimular ni fingir; el peso de la culpa anonada la voluntad. (II, 3, p. 107)

Las nieblas de la ambigüedad van poblando el territorio de las relaciones personales donde antes había claridad. El drama entero reside para los personajes en averiguar qué piensan realmente los otros de ellos. Qué saben y qué no saben de sus conductas. Si se presentan como son o están interpretando. A Edmundo y Alicia les atenazan estas preguntas en el acto primero: ¿Sospecha o sabe Yorick su relación adúltera? ¿Y Walton? Instalados en la duda hurgan en cada una de las frases tratando de encontrar su sentido exacto (I, 5). Al comenzar el acto segundo queda contestada tras la conversación con Shakespeare que Walton lo sabe, pero ¿qué hará? Por el contrario, como muestra el fragmento que acabo de citar, Yorick está ahora encontrando la respuesta. Acosa a Edmundo (II, 3), a Alicia (II, 6). Duda de ellos y de Walton (II, 3, p. 108) o de Shakespeare (II, 7 y 8 ). Y llega a saber por Walton que su mujer le es infiel, aunque no sabe con quien (II, 9).

La ambigüedad domina tanto en el terreno de las relaciones personales como en el terreno del arte. El temor a lo desconocido condiciona por igual en los dos dominios: el actor frente al reto nuevo de crear un personaje diferente saliendo de sus recursos habituales. Yorick vive la zozobra de intentar saber si logrará triunfar con un personaje trágico o Walton como confidente. Las personas no sabiendo cómo resolver sus nuevas situaciones afectivas escindidas entre lo establecido y lo censurado socialmente: Edmundo y Alicia atormentados por los remordimientos (I, 5). Yorick teniendo que asumir el adulterio de su esposa. Walton su turbio pasado.

Tamayo elige para ubicar su drama un momento histórico del que se tiene una imagen profundamente teatralizada pero no escribe un drama histórico al estilo del primer romanticismo con escasa información histórica y sobre los personajes que hace comparecer en las tablas. Por el contrario, atenúa los aspectos espectaculares exteriores del drama-salvo en el momento culminante de confluencia de las dos tramas-y conduce a los 
espectadores más al ámbito privado de los personajes que al público. Tamayo vence la tentación de convertir su drama en una lección de historia teatral y literaria. O mejor dicho, encuentra la manera de que las alusiones históricas no entorpezcan el desarrollo de la acción dramática ${ }^{9}$. La lección de historia teatral es muy otra: mostrar el teatro por dentro, convertido en vida por quienes viven de él en los distintos oficios y lo hacen posible: asistimos a las luchas por el reparto, a los ensayos (I, 2). A la inseguridad de los actores en sus papeles: Yorick en todo su proceso; Walton en su nuevo papel de confidente (II, 1).

Un drama nuevo es un drama histórico que se desarrolla en el ámbito de lo doméstico. Salvo el momento en que la mentira (la ficción dramática) revela la realidad (la traición familiar) todo sucede fuera del escenario, aunque bien es cierto que entre gentes de teatro que viven en cada momento en el límite de la mentira teatral. Y esto ocurre porque el teatro lo ha invadido todo, persigue a los personajes hasta los reductos más recónditos. A la casa donde viven los cómicos en los actos primero y segundo. A los camerinos en la primera parte del acto tercero. Se puede decir que en desarrollo del drama asistimos a cómo lo más íntimo y desde lo más íntimo (la casa, el camerino) es sacado a lo público: el teatro, el escenario.

Desde la primera réplica es evidente la omnipresencia de lo teatral: Yorick ha arrastrado hasta su casa a Shakespeare ¿para qué? Para convencerlo de que le conceda el papel de marido ultrajado en el nuevo drama. ¿Qué le responde Shakespeare? Lleva en la mano el manuscrito de un nuevo drama, pero además le dice: «Aguárdanme en casa muchos altísimos personajes, que por el solo gusto de verme vienen desde el otro a este mundo.» (p. 71)

Es decir, anda elucubrando sobre sus criaturas de ficción, tal y como confirma la réplica siguiente de Yorick. El teatro lo es todo para estos personajes, impregna sus vidas absolutamente. El teatro en sus vidas no acaba con la función o con el ensayo, sino que los acompaña en su vida privada. Es también su vida privada. Los espera en casa. Llena sus palabras y sus pensamientos.

Toda su conversación por ello gira en torno a la pieza que acaban de leer, a la peculiar forma de comportarse quienes viven del teatro, comidos por la envidia y de donde es difícil salir:

Yorick.-Entren todos y salga el que pueda. ¡Qué murmurar unos de otros! ¡Qué ambicionar éstos y aquéllos antes el ajeno daño que la propia satisfacción! ¡Qué juzgarse cada cual único y solo en el imperio de la escena!

Shakespeare.-Engendra ruindades la emulación; mas por ella vence el hombre imposibles. Déjala revolcarse en el fango, que alguna vez se levantará hasta las nubes. (p. 73) 


\section{Un drama nuevo, de Manuel Tamayo y Baus...}

Este es el gran asunto de Un drama nuevo: la enfermedad incurable del teatro, que arrasa y devasta a quienes se dedican a él. Desde el primero al último. En esta batalla no se salva ni el Traspunte. Produce la ceguera para lo más evidente o revela lo más oculto. Yorick se entusiasma ya en estos primeros momentos del drama recordando a Alicia y Edmundo representando a Romeo y Julieta: «¡Cómo representan los dos el Romeo y Julieta! Divinos son estos dos héroes, a que dio ser tu fantasía, más divinos aún cuando Alicia y Edmundo les prestan humana forma y alma verdadera! ¡Qué ademanes, que miradas, qué modo de expresar el amor! Vamos, aquello es la misma verdad.» (p. 73)

$\mathrm{Y}$ ciertamente lo es, aunque en su ceguera Yorick no haya sido capaz de advertirlo, como ya sugiere dirigiéndose al público Shakespeare: «Desdichado Yorick» (p. 73). La devastadora máquina ya está en marcha. Cada réplica está impregnada de dobles sentidos que resultan transparentes u opacos según sea quien la interprete. Y según lo haga desde la escena o desde el lugar donde se supone que se encuentra el público a quien se dirige Shakespeare en este y otros momentos. Además de ser el director de la compañía, Tamayo le ha dotado de unas características muy especiales. Shakespeare encarna el genio dramático: tiene una mirada que le permite adivinar y aun descubrir los conflictos con una habilidad especial. Dirige su compañía de teatro, a sus cómicos, pero en realidad lo hace tanto dentro del teatro como fuera de él y por ello no es extraño que sea él quien explique al público lo acontecido al final. Desde la primera escena conoce las tensiones y las traiciones de unos y otros ${ }^{10}$. Pero el demiurgo se enreda con los cordelillos con que mueve sus personajes y se descubre atrapado él mismo en el juego teatral. Todo puede ser otra cosa y una vez puesta en marcha la máquina es imposible pararla. Y no es que no lo intente. Ya en la escena sexta del primer acto busca con Alicia y Edmundo la forma de resolver la situación: sabe y les revela su amor. Les exige que cumplan con su deber. Esta escena es un paréntesis para las confidencias sin ambigüedades. Todo es transparencia. Confiesan los dos enamorados cómo han llegado a tal situación a pesar de sus esfuerzos por eludirla. El amor impuso su dominio invencible y por más que trataron de eludirlo los cercó hasta hacer que se declararan su pasión mientras representaban Romeo y Julieta ${ }^{11}$. Y sabe que está también en el secreto Walton, a quien intentará convencer de que no cumpla sus amenazas descubriéndole a Yorick que no es solo un marido ultrajado en el papel que representa en el nuevo drama, sino en la realidad.

Introducir a Shakespeare como personaje dramático implicaba una elección comprometida y que cualquier lectura posterior tenga que valo- 
rar las razones posibles de esta elección y su acierto o fracaso. Cuando Shakespeare comparece como personaje en un escenario lo hace el teatro mismo encarnado en su máximo representante después de la glorificadora exaltación que vivió su figura durante el primer romanticismo ${ }^{12}$. Los escenarios de los distintos países se llenaron de personajes modélicos de su pasado nacional, incluidos artistas y dramaturgos ${ }^{13}$. Pero Tamayo, ni era inglés (y por tanto propenso a ofuscarse ante una gloria patria) ni la exaltación preside su escritura. Es el modelo supremo de dramaturgo a quien convoca a escena, para mostrar su grandeza, pero también sus límites, menores como dramaturgo que como director de escena, que es como aparece en Un drama nuevo. Es decir, la libertad absoluta del creador de dramas es contrapesada por las limitaciones del práctico de teatro que debe proporcionarles virtualidad escénica, pugnando entre otros con los actores.

En vano trata Shakespeare de disuadir a Yorick de su deseo de hacer un papel trágico. Quiere éste demostrar que es capaz de prestar su cuerpo para que sobre el escenario vivan no sólo personajes cómicos -por lo que se le admira- sino también trágicos. Ignora que su triunfo en el teatro lo logrará con la escenificación de su fracaso absoluto en la vida. En vano intentará Shakespeare evitar que Walton cumpla su venganza. $\mathrm{Pa}-$ rece al comienzo del segundo acto que lo ha convencido de que no debe revelar su desgracia a Yorick, pero a la postre lo hará, acosado por el propio Yorick (II, 9). Por encima de la voluntad de los personajes sobrevuela la fatalidad de sus destinos. Son arrastrados a conocer lo que menos quisieran conocer.

De las dos partes del acto tercero ha sido mucho más comentada la segunda que la primera. Sin embargo, acaso era más difícil de resolver esta, preparando verosimilmente el momento culminante del asesinato en escena. Tamayo presenta la vida entre bastidores en la función de estreno. Las zozobras del autor novel, que ve como se va concretando el éxito. Los celos de Walton que confirma sus temores de que Yorick pueda triunfar como actor trágico. Las inseguridades antes de salir a escena. La envidia tejiendo comentarios mordaces ${ }^{14}$. Los ecos de las reacciones del público... Y paralelamente, la preparación por parte de Walton de su venganza, que consistirá en sustituir la carta reveladora del adulterio en la ficción por la carta que ha escrito Edmundo para Alicia concretando el momento de su fuga y que entregada en la segunda parte a Yorick, le abrirá los ojos definitivamente.

Diálogo y atrezzo - los actores visten naturalmente como los personajes que están representando- van disponiendo las cosas de tal modo que 
Un drama nuevo, de Manuel Tamayo y Baus...

nada quede suelto u oscuro en el momento culminante. El juego teatral con las dos cartas - la de la ficción y la de Edmundo para Alicia- tiene la sutileza de este recurso en las mejores comedias de enredo.

La segunda parte no hace sino apurar las posibilidades que han ido perfilándose en estas escenas, fundiéndose por completo ficción y realidad según acota Tamayo por si no fuera ya evidente: «Desde este momento la ficción dramática queda convertida en viva realidad, y tanto en Yorick como en Alicia y Edmundo se verán confundidos en una sola entidad el personaje de invención y la persona verdadera.» (p. 139)

Por si hubiera alguna duda de quien es quien, Tamayo ancla una vez más los personajes en el reparto del drama que representan. De los 129 versos que representan hace que en los siete primeros haya vocativos nominales que designan a los personajes que representan: Walton dos veces como Landolfo, Alicia como Beatriz, Edmundo como Manfredo. Importa que nada enturbie el sentido de lo representado. La rápida y tensa escena acabará con Edmundo muerto sobre la escena y el drama con la explicación de Shakespeare:

¡Señores, ya lo veis! (...) No puede terminarse el drama que se estaba representando.

Yorick, ofuscada su razón por el entusiasmo, ha herido realmente al actor que hacía el papel de Manfredo. Ni es esta la única desgracia que el cielo nos envía. También

ha dejado de existir el famoso cómico Walton. Acaban de encontrarle en la calle con el pecho atravesado de una estocada. Tenía en la diestra un acero. Su enemigo ha debido matarle riñendo cara a cara con él. Rogad por los muertos. ¡Ay, rogad también por los matadores! (p. 144)

Se ha cumplido así inexorablemente -como si de un drama shakespereano se tratara- lo que se venía anunciando: las muertes por venganza de dos personajes: Edmundo, víctima de la venganza del honor ultrajado de Yorick; y Walton muerto por Shakespeare en lucha leal por no haber respetado su compromiso. Sea como fuere, la maquinaria teatral ha funcionado inexorable. El teatro llenó sus vidas, pero para hacerlo devasta su intimidad y hasta les priva de la vida.

El final de Un drama nuevo está lleno de perplejidades e interrogantes. Perplejos quedan el público y los propios actores. ¿Realmente es tan peligroso este arte para quienes se dedican a él? ¿Juega quien juega al teatro a un juego tan peligroso como la ruleta rusa?

$\mathrm{Y}$ una última cuestión que tiene que ver con la historia literaria: es un lugar común en las historias del teatro español considerar que dramaturgos como Tamayo y Baus se distanciaron de la estética desmesurada y melodramática del primer romanticismo, instaurando en los escenarios españoles una cierta naturalidad. La lectura de piezas representativas de la alta comedia lo desmiente. El desplazamiento producido en aquellos 
años fue más de los asuntos históricos a los contemporáneos, que de la entonación melodramática a la entonación realista. La tensión pasional no es muy diferente en unos y en otros. Un drama nuevo es uno de los ejemplos más nítidos de la dificultad de diferenciar drama histórico y drama de costumbres contemporáneas. Es una mixtura de ambos. Su temática es tanto histórica como de drama burgués donde prima la representación de lo privado. La representación de las paradojas de las gentes del teatro de todo tiempo, su peculiar forma de vivir con un pie en la realidad y el otro en la ficción, caminando por la vida a trompicones, confundiendo con frecuencia a qué pie corresponde cada paso.

\section{Notas}

1 Paradójicamente, sin embargo, carecemos aún de una edición crítica del texto. Labor nada fácil de llevar a cabo porque se conservan numerosos manuscritos del drama -parte de ellos autógrafos- y desde las primeras ediciones se introducen cambios, que resaltaron cada vez más la teatralidad. Véase, Isabel Román, «La significación de Un drama nuevo, de Tamayo y Baus, a través de su proceso de composición", en El siglo XIX... y la burguesía también se divierte. Actas del I congreso de Historia y crítica del teatro de comedias, Ayuntamiento de El Puerto de Santa María y Fundación Pedro Muñoz Seca, 1995, pp. 178-185.

2 Manuel de la Revilla, Obras, Madrid, 1883, p. 75.

${ }^{3}$ Leopoldo Alas, Solos de Clarín, Madrid, 1881, p. 35. En la exégesis de la relación de los personajes de Un drama nuevo con otros de Shakespeare poco más ha añadido la crítica posterior. Neale H. Tayler añade la comparación entre Walton y Yago (Las fuentes del teatro de Tamayo y Baus. Originalidad e influencias, Madrid, 1959, pp. 179-187).

4 Ramón Esquer Torres, “Tamayo y Baus y la política del siglo XIX», Segismundo, 1, 1965, pp. 71-91.

5 Tanta ostentación de habilidad escénica le llevó a preguntarse a Robert E. Lott sobre si no acaba constituyendo una de sus limitaciones: "On Mannerism and Mannered Approaches to Realism in Un drama nuevo, Consuelo, and Earlier Nineteenth-Century Plays", Hispania, LIV, 1971, pp. 844-855.

6 Analizó este aspecto con cuidado Lester G. Crocker, «Techniques of Ambiguity in Un drama nuevo", Hispania, 39, 1956, pp. 412-418.

7 No voy a insistir por ello aquí en las posibles fuentes. Véanse, Roy Temple House, "Lope de Vega and Un drama nuevo", Romanic Review, XIII, 1922, pp. 84-87; Paul P. Rogers, "Galdós and Tamayo Letters-substitution device", Romanic Review, 42-2, 1954, pp. 115-120. Neale H. Tayler, Las fuentes del teatro de Tamayo y Baus. Originalidad e influencias, Madrid, 1959. Y Ramón Esquer Torres, El teatro de Tamayo y Baus, Madrid, C.S.I.C., 1965.

8 Manuel Tamayo y Baus, Un drama nuevo, Madrid, Taurus, 1982, p. 72. En adelante se cita por esta edición, indicando entre paréntesis las páginas en el texto y cuando se trata de citas más amplias, remitiendo al acto y escena correspondientes.

9 Yorick, por ejemplo, enhebra citas de dramas de Shakespeare en su conversación: Romeo y Julieta interpretados por Alicia y Edmundo (p. 73), Hamlet y su famoso monó- 


\section{Un drama nuevo, de Manuel Tamayo y Baus...}

logo (p. 75). Shakespeare se refiere a sus dramas Otelo y Macbeth (p. 95). El Traspunte recuerda a Walton representando a Macbeth (p. 126).

${ }^{10}$ Es como un posible autorretrato de Tamayo: el dramaturgo consagrado que se dispone a mostrar los mecanismos del teatro. Tamayo debía sentir a esas alturas de su trayectoria la tentación de codearse con los grandes del Parnaso. El destino del dramaturgo es pasarse la vida contemplando el actuar de los hombres para trasladarlo al escenario. En boca del autor novel no faltan, con todo, unas frases que contrapesan también esto: “iShakespeare!... ¡Oh, Shakespeare!... No faltará quien trate de hacerle sombra conmigo. Pero yo jamás creeré... No; jamás. Yo soy modesto..., muy modesto.» (p. 123)

De su admiración por el dramaturgo inglés, dejó también testimonio en su discurso de ingreso en la Real Academia de la Lengua: De la verdad considerada como fuente de belleza en la literatura dramática (1859).

11 Tamayo utilizó aquí con habilidad un recurso muy repetido en la literatura de la época, pero que tiene larga tradición: lo que Andrés Soria llamó la vida de la letra al analizar este tópico en la rima XXIX de Bécquer: "La vida de la letra", Revista de Literatura, XXVIII, 1965, pp. 67-73. Leyendo-aquí interpretando la pareja shakespereana- a los amantes se les revela su intensa pasión. Y los personajes interpretados ponen palabra a sus pasiones. Aunque la revelación de su amor es solamente contada, es uno de los momentos más intensos del drama, equiparable a mi entender al de la confluencia de las dos tramas.

Y como de apurar procedimientos se trata, Tamayo idea otra situación en la que un relato es el mecanismo revelador: en su pugna para sacarle la verdad, Yorick le cuenta su propia historia a Walton como si le hubiera sucedido a otro (II, 9).

12 Roberto G. Sanchez ya señaló este valor simbólico y arquetípico de Shakespeare en el drama: "Los comediantes del XIX: Un drama nuevo", Hispanic Review, 48, 1980, p. 438. Véase también, José Alberich «El papel de Shakespeare en Un drama nuevo de Tamayo", Filología Moderna, X, n 39, 1970, pp. 301-322.

Sigue siendo útil la consulta de Alfonso Par, Shakespeare en la literatura española, Barcelona, Victoriano Suárez, 1935. No sólo el teatro sino las artes plásticas entraron a saco en la vida y en la obra shakespereana. Basta recordar algunos cuadros: José de Madrazo, «Escena de Hamlet». Valeriano Bécquer, "Ofelia». Eduardo Rosales, "Hamlet y Ofelia» (1871). Antonio Muñoz Degrain, «Desdémona» (1887), etc. Véase, José Luis Díez, "El mundo literario en la pintura del siglo XIX del Museo del Prado", en El mundo literario en la pintura del siglo XIX del Museo del Prado, Madrid, Ministerio de Cultura, 1994, pp. 93-120.

La visión.mitificada del dramaturgo puede seguirse en incontables artículos incluidos en las revistas y aun en otras prácticas sociales como las que componen la poética de la muerte y la exaltación del genio: retratos, vaciados en yeso, etc. En fechas cercanas al estreno de Un drama nuevo, por ejemplo, El Museo Universal (1866) ofrecía un "Retrato de Shakespeare vaciado en yeso del natural."

Sobre estos usos sociales y su alcance simbólico, véanse los catálogos: À fleur de peau. Le moulage sur nature au XIXe siècle, Paris, Musée d'Orsay, 2001. Y Le dernier portrait, Paris, Musée d’Orsay, 2002. Faltan estudios similares de lo acontecido en España.

13 Véanse, para España: Susana Vedovato, “Los artistas en las tablas. Trayectoria de un tema en la época romántica", Teatro romántico español, Bologna, 1984, pp. 163-178. Narciso Alonso Cortés, Quevedo en el teatro y otras cosas, Valladolid, Imprenta del Colegio Santiago, 1930. Joaquín Álvarez Barrientos, «Pedro Calderón de la Barca en los siglos XVIII y.XIX. Fragmentos para la historia de una apropiación", en Estado actual de los es- 


\section{Jesús Rubio Jiménez}

tudios calderonianos, ed. de Luciano García Lorenzo, Kassel, Reichenberger, 2000, pp. 279-324.

14 Se va haciendo así patente la tesis del drama: el Traspunte alude a la envidia de Walton en varias ocasiones. Shakespeare con su autoridad indiscutible lo recalca: «Sí; la envidia tiene tu alma entre sus garras; la envidia, que llora el bien ajeno y se deleita en el propio mal; la envidia, que fuera la desgracia más digna de lástima si no fuera el más repugnante de los vivos; la envidia, oprobio y rémora de la mente, lepra dèl corazón.» (p. 135). 